from the membrane electrical resistance. Because the $\mathrm{P}_{\mathbf{K}}+$ value without enniatin $B$ is very low, a small alteration in the membrane structure induced by the presence of enniatin $B$ may be sufficient to increase $\mathbf{P}_{\mathrm{K}}+$ many times. The thiourea permeability coefficient, which is high compared with $\mathrm{P}_{\mathbf{K}}+$, may at the same time undergo a relatively small change. It is interesting that Cass and Finkelstein ${ }^{8}$ have detected no effect on the diffusion of tagged water by using a protein moleculo which considerably lowers the electrical resistance in lipid mombranes.

We concludo that, as well as having a selective influeneo on cation permeability as demonstrated by Mueller and Rudin ${ }^{4}$, enniatin $B$ affects the permeability of an unionized molecule as thiourea. The mechanism of enniatin $B$ action on thiourea permeability has not been clarificd, however. It scems possible that the interaction between the peptide and the lipids makes the membrane more polar, so as to increase thiourea permeability.

I thank Dr P. Läuger and Dr W. Lesslauer for advice and criticism and Hoffmann-La Roche AG for providing enniatin $B$. I was supported by a fellowship from NATO.

Institute of Physical Chemistry, Claudro LipPE*

University of Basle,

Switzerland.

Received January 30; revised February 12, 1968.

* Permanent address: Istituto di Fisiología Generale, Università di Milano, Italy.

1 Chapp.ll, J. B., and Crofts, A. R., Biochem. J., 95, 393 (1965).

Pressman, B. C., Proc. US Nat. Acad. Sci., 53, 1076 (1965).

s Harold, F. M., and Baarda, J. R., J. Bacteriol., 94, 53 (1967)

4Mucller, P., and Rudin, D. O., Biochem. Biophys, Res. Commun., 26, 398 (1967).

s Pangborn, M. C., J. Biol, Chem, 188, 471 (1951).

- Lüuger, P., Lessiauer, W., Marti, F., and Richter, J.. Biochim. Biophys. Acta, 135, 20 (1967).

? Vreeman, H. I., Konikl. Ned. Akad. Wet. Ser. B, 69, 564 (1966).

${ }^{8}$ Cass, A., and Finkeistein, A., J. Gen. Physiol., 50, 1765 (1967).

\section{Occurrence of the Neurolathyrogen a-Amino- $\beta$-oxalylaminopropionic Acid in Two Species of Crotalaria}

The toxicity of various species of Crotalaria to animals, and on occasion to man, has been widely reported and several different pyrrolizidine alkaloids have been isolated from or identified in plants of this genus. Among specios which have been reported as toxic are Crotalaria incana L. and $C$. mucronata Desv. ${ }^{1}$ and both are known to synthesize alkaloids ${ }^{2,3}$.

The possibility that toxic compounds other than alkaloids are present in these two species was suggested when extracts of their seeds (alone of twenty-seven species analysed) were found to contain a ninhydrinreacting compound which occupiod the same position on $2 \mathrm{D}$ chromatograms as $\alpha$-amino- $\beta$-oxalylaminopropionic acid (the neurotoxic amino-acid common to those species of Lathyrus responsible for classical lathyrism in man and domestic animals $\left.{ }^{4-6}\right)$. The identity of this compound as the $\beta$-oxalylamino-acid was established by co-chromatography with authentic material in six solvent systems and ionophoresis at four $p \mathrm{H}$ values. Confirmation was obtained by eluting the compound from ionophoresis papers, hydrolysing it in acid solution and identifying the products as $\alpha \beta$-diaminopropionic acid (by co-chromatography, ionophoresis and colour reactions ${ }^{7,8}$ ) and oxalic acid (by reaction with alkaline potassium permanganate and with potassium ferrocyanide-ferric ammonium sulphate reagent ${ }^{2}$ ).

By subjecting the original extracts to high-voltage ionophoresis on paper at $p H \mathbf{H} 3.0$ it was possible to resolve the oxalylamino-acid "stripe" into a major faster-moving component corresponding to $\alpha$-amino- $\beta$-oxalylaminopropionic acid and a minor component (judged by colour yield with ninhydrin) which showed identical ionic mobility with the isomeric $\alpha$-oxalylamino- $\beta$-aminopropionic acid previously identified in Lathyrus sativus, $L$. cicera and $L$. clymenum ${ }^{10}$. Like tho $\alpha$-oxalyl compound in the Lathyrus species, the slower moving component in the Crotalaria extracts failed to chelato with cupric ions $^{11}$ and reacted less rapidly with ninhydrin.

The occurrence of $\alpha$-amino- $\beta$-oxalylaminopropionic acid in a second genus of the Leguminosae belonging to the Genisteae rather than to the Vicieae suggests that this neurotoxic compound may be more widely distributed than studies of the Vicieae (in which it has only been found in certain species of Lathyrus) have suggested.

I thank Dr C. R. Gunn of the US Department of Agriculture for providing seed for this work.

Department of Biochomistry,

E. A. BELI

King's College,

Univorsity of London, London, W.C.2.

Received March 14, 1968.

${ }^{1}$ Kingsbury, J. M., Poisonous Plants of the United States and Canada, 320 (Prentice Hall, 1964).

${ }^{2}$ Adarns, R., and Van Duuren, B. L., J. Amer. Chem. Soc., 75, 4631 (1953).

${ }^{3}$ Sharma, R. K., Khajuria, G. S., and Atal, C. K., J. Chromatog., 19, 433 (1965)

' Rao, S. L. N., Adiga, P. R., and Sarma, P. S., Biochemistry, 8, 432 (1961).

${ }^{5}$ Murti, V. V. S., Seshadri, T. R., and Venkitasubramanian, T. A., Phytochemistry, 3, 73 (1964).

B Bell, F. A., Nature, 203, 378 (1964).

7 Bcll, E. A., and 'Tirimanna, A. S. L., Biochem. J., 97, 104 (1965).

${ }^{8}$ Seneviratne, A. S., and Fowden, L., Phytochemistry (in the press).

'Smith, I., Chromatographic and Electrophoretic Techniques, 1, 281 (Heinemaun, 1960).

${ }^{10}$ Bell, E. A., and O'Donovan, J. P., Phytochemistry, 5, 1211 (1966).

${ }^{11}$ Larsen, P. O., and Kjaer, A., Biochim. Biophys. Acta, 38, 148 (1960).

\section{Synthetic I-N-Carbamylhemicystine-2-O- methyltyrosine-oxytocin ( $\mathrm{N}$-Carbamyl-O- methyl-oxytocin): a Specific Antagonist to the Actions of Oxytocin and Vasopressin on the Uterus and Mammary Gland}

Cyanate reacts with the terminal amino groups of proteins and peptides to form $N$-carbamyl derivativos ${ }^{1}$. Bisset, Poisner and Smyth ${ }^{2}$ tested the biological activity of oxytocin which had been carbamylated by reaction with cyanate. The products of the reaction specifically inhibited the response of the isolated rat uterus, rat blood pressure and chicken blood pressure to oxytocin but had a weak stimulant action, like that of oxytocin itself, on the rat uterus in situ and on tho guinoa-pig mammary gland, both isolated and in situ. At the time, these effects were attributed to the formation of $\mathrm{l}-\mathrm{N}$. carbamyl-oxytocin ${ }^{3}$. In later work, however, Smyth 4 showed that the inhibitory properties were caused by the presence in the reaction mixture of a trace of a dicarbamyl derivative of oxytocin, $\mathrm{N}$-carbamyl-O-carbamyl-oxytocin, in which not only the terminal amino $\left(\mathrm{NH}_{2}\right)$ group of the hemicystine residue but also the phenolic hydroxyl $(\mathrm{OH})$ group of the tyrosine residue had undergone carbamylation, and he went on to describe the preparation of a series of stable, doubly modified analogues which were specific antagonists of oxytocin without intrinsic activity on the isolated uterus ${ }^{4,5}$. 1- $N$-Carbamyl-oxytocin, in contrast, was shown to be a weak agonist with no inhibitory action ${ }^{4}$.

The $O$-carbamyl substituent is unstable at physiological $p \mathrm{H}$ (ref. 4). A synthetic analogue, $O$-methyloxytocin, which has a stable substituent in the tyrosine hydroxyl group, was prepared independently by Law and du

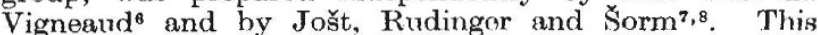

